\title{
Analysis of perioperative cardiac arrest in a rural hospital in Korea
}

\section{Young-Mu Kim', Jae-Ho Lee', Hyun-Soo Kim', Jin Sun Kim', and Hong-Seuk Yang ${ }^{2}$}

Department of Anesthesiology and Pain Medicine, ${ }^{1}$ Gangneung Asan Hospital, University of Ulsan College of Medicine, Gangneung, 'Daejeon Sun Medical Center, Daejeon, Korea

\begin{abstract}
Background: Perioperative cardiac arrest has been studied in many countries but few related studies have been conducted in Korea. Previous studies were not applicable to rural hospitals due to differences in the demographics between the regions. In the present study, the incidence, mortality, and related factors of perioperative cardiac arrest in a hospital in Youngdong province were analyzed and compared with previous research.
\end{abstract}

Methods: A retrospective study was conducted from the January 1, 2012, to December 31, 2018, on patients who underwent both anesthesia and surgery in our hospital. Patients who received local anesthesia were not included in the study. The collected data included the patient characteristics, anesthesia methods, the American Society of Anesthesiologists physical status, surgical department, emergency status, traumatic status, pre- and post-cardiac arrest medical records, and patient outcomes.

Results: A total of 57,746 patients received anesthesia and underwent surgery during the study period, and 28 patients (4.85 per 10,000 anesthesia cases) received cardiopulmonary cerebral resuscitation (CPCR) during or within $24 \mathrm{~h}$ of surgery. Eight patients survived and twenty patients died (3.46 per 10,000 anesthesia cases). There were three anesthesia-related arrests and all of these patients survived. When limiting the analysis to patients with intraoperative CPCR, the incidence and mortality were 1.56 , and 1.39 per 10,000 anesthesia cases, respectively.

Conclusions: The incidence and mortality of perioperative cardiac arrest in our hospital were higher than those in a recent study in Seoul, demonstrating a regional gap in Korea.

Keywords: Anesthesia; Heart arrest; Incidence; Mortality; Resuscitation.

\section{INTRODUCTION}

Fortunately, the perioperative mortality rate is low, but death remains the most serious complication caused by surgery [1]. According to studies released after the 2000s, the incidence of perioperative cardiac arrest was 0.5 to 96.4 per 10,000 anesthesia cases, which showed a wide varia- tion [1-5]. Even though it is difficult to compare those data accurately because of heterogeneous research methods, the incidence of perioperative cardiac arrest tended to decline over time as countries developed $[1,3,6]$.

Chang et al. [7], Choi et al. [2], and Lee et al. [8] reported studies of perioperative cardiac arrest in Korea. Each study, however, was either a study conducted for a long time ago

This is an Open Access article distributed under the terms of the Creative Commons Attribution Non-Commercial License (http://creativecommons.org/licenses/by-nc/4.0) which permits unrestricted non-commercial use, distribution, and reproduction in any medium, provided the original work is properly cited.

Copyright (C) the Korean Society of Anesthesiologists, 2020 
[7], conducted at a single large hospital in a capital city (Seoul) [2], or targeted on children only [8]. One study [2] performed in relatively recent years had advantage that targeted all age groups. However, since it was conducted at a large hospital in Seoul, the results may not apply to general hospitals in rural areas. Because the demographic characteristics and patient populations of different cities are expected to differ from each other, the present study analyzed the data collected from Gangneung Asan hospital located in Youngdong province. We evaluated the incidence and the mortality rate of perioperative cardiac arrest and related factors. Lastly, the data were compared with the previous study conducted in Seoul, and we investigated whether there was a regional gap in the incidence and mortality rate of perioperative cardiac arrests.

\section{MATERIALS AND METHODS}

The present study was approved by the Institutional Review Board (IRB) of our hospital (no. GNAH 2019-07-010). It was conducted on patients who underwent both anesthesia and surgery together from January 1, 2012, to December 31, 2018. After extracting a group of patients with cardiopulmonary cerebral resuscitation (CPCR) codes in their medical record, the patients who received CPCR within $24 \mathrm{~h}$ after surgery were selected for the study. A total of 57,746 patients who received anesthesia and surgery were registered during the study period. Perioperative cardiac arrest was defined as a condition in which CPCR was performed during surgery or within $24 \mathrm{~h}$ of surgery. CPCR was defined as the performance of either closed-chest compressions or open cardiac massage. Cases in which CPCR was performed prior to entering the operating room (OR) or the cardiac arrest occurred prior to the induction process in OR were excluded. Patients with missing anesthesia records or with written "Do not resuscitate" instructions prepared before surgery were also excluded.

The emergency status, traumatic status, surgical duration, onset of cardiac arrest, the pre-and post-cardiac arrest medical records, and data including the characteristics of patients, surgical departments, anesthesia methods, American Society of Anesthesiologists physical status (ASA PS) classification, and comorbidity status of the selected patients were evaluated. By reviewing the anesthesia records, the intubation status before entering the OR, endotracheal tube (ETT) maintenance on leaving the OR, arterial cannulation, central venous cannulation, and information on epinephrine injections during surgery were collected. The surgical duration was defined from the start of anesthesia to the end of anesthesia according to the anesthesia records, and the regular working hours were defined from 8 a.m. to 6 p.m. on weekdays. The duration of CPCR was divided into two groups by $10 \mathrm{~min}$ (within $10 \mathrm{~min}$ or more than $10 \mathrm{~min}$ ) because the likelihood of a favorable functional recovery significantly decreases when the duration of CPCR is longer than 10 to $15 \mathrm{~min}$ [9]. The survival was defined as the patient was finally resuscitated for $48 \mathrm{~h}$ after surgery. Variations between demographics and the incidence of cardiac arrest or between demographics of the two hospitals [2] were compared using $\chi 2$ tests. Other statistical analyses for survival rate were performed using Fisher's exact test. All statistical analyses were conducted using IBM SPSS Statistics Subscriptions for Microsoft Windows 64-bits Build 1.0.0.1327 (IBM Co., USA). A P value below 0.05 was considered statistically significant.

\section{RESULTS}

A total of 57,746 patients who received anesthesia and surgery at the same time were enrolled, 43,583 underwent general anesthesia, 11,926 underwent spinal anesthesia, 2,013 underwent peripheral nerve blocks, 145 underwent epidural anesthesia, 58 underwent monitored anesthesia care, and 21 underwent combined spinal-epidural anesthesia. The characteristics of the anesthetized patients are shown in Table 1.

A total of 28 cases of perioperative cardiac arrest occurred during the 7 -year retrospective study period. Of the 28 CPCR cases, 20 patients $(71.4 \%)$ died and eight patients (28.6\%) survived. The incidence of perioperative cardiac arrest was 4.85 per 10,000 anesthesia cases, whereas the mortality was 3.46 per 10,000 anesthesia cases. The incidence of CPCR was significantly different by age $(\mathrm{P}=$ $0.021)$, ASA PS classification $(P<0.001)$, or elective/emergency surgery $(\mathrm{P}<0.001)$. Males showed higher CPCR incidence than females (5.18 vs. 4.52 per 10,000 anesthesia cases), but there was no significant difference $(P=0.851)$. When the ASA PS classification increased, the incidence of CPCR tended to increase. The survival rate was significant for elective/emergency surgery ( $50 \% / 12.5 \%, \mathrm{P}=0.044)$.

The rate of survival was higher in patients who were not intubated before entering the OR (33.3\%) or were extubated when leaving the OR (62.5\%) compared to patients who were already intubated before entering the OR (14.3\%) or were still intubated when leaving the OR (15\%) (Table 2). 
Table 1. Incidence and Characteristics of 57,746 Anesthetized Patients

\begin{tabular}{|c|c|c|c|c|c|}
\hline \multirow[b]{2}{*}{ Characteristics } & \multirow{2}{*}{$\begin{array}{l}\text { Total anesthesia } \\
\quad(n=57,746)\end{array}$} & \multicolumn{4}{|c|}{ Cardiac arrests $(n=28)$} \\
\hline & & Survival/Cardiac arrest & $\begin{array}{c}\text { Incidence } \\
\text { (per 10,000) }\end{array}$ & $\begin{array}{l}\text { P value* for } \\
\text { incidence }\end{array}$ & $\begin{array}{l}P \text { value }{ }^{\dagger} \text { for } \\
\text { survival }\end{array}$ \\
\hline \multicolumn{6}{|l|}{ Age (yr) } \\
\hline$<65$ & $40,852(70.7)$ & 3/14 (21.4) & 3.42 & $0.021^{\ddagger}$ & 0.678 \\
\hline$\geq 65$ & $16,894(29.3)$ & $5 / 14(35.7)$ & 8.29 & & \\
\hline \multicolumn{6}{|l|}{ Sex } \\
\hline Male & $28,979(50.2)$ & 5/15 (33.3) & 5.18 & 0.851 & 0.686 \\
\hline Female & $28,767(49.8)$ & 3/13 (23.1) & 4.52 & & \\
\hline \multicolumn{6}{|l|}{ ASA PS class } \\
\hline I & 21,914 (37.9) & $0 / 1(0)$ & 0.46 & $<0.001^{\ddagger}$ & - \\
\hline ॥ & $28,308(49.0)$ & $5 / 11(45.5)$ & 3.89 & & \\
\hline III & $4,681(8.1)$ & $3 / 10(30)$ & 21.36 & & \\
\hline IV & $376(0.7)$ & 0/4 (0) & 106.38 & & \\
\hline V & $27(0)$ & $0 / 2(0)$ & 740.74 & & \\
\hline $\mathrm{VI}$ & $1(0)$ & - & - & - & - \\
\hline Other & $2,439(4.2)$ & - & - & - & - \\
\hline \multicolumn{6}{|l|}{ Elective surgery } \\
\hline Yes & $51,158(88.6)$ & $6 / 12(50)$ & 2.36 & $<0.001^{\ddagger}$ & $0.044^{\ddagger}$ \\
\hline No & $6,588(11.4)$ & $2 / 16(12.5)$ & 24.29 & & \\
\hline \multicolumn{6}{|l|}{ Trauma } \\
\hline Yes & - & $0 / 8(0)$ & - & - & 0.063 \\
\hline No & - & $8 / 20(40)$ & - & - & \\
\hline
\end{tabular}

Values are presented as number (\%). ASA PS: American Society of Anesthesiologists physical status. *Statistical analysis was conducted using $x^{2}$ test. ' Statistical analysis was conducted using Fisher's exact test. ${ }^{\ddagger} \mathrm{P}$ value $<0.05$, statistically significant.

Table 2. Anesthetic Management of Perioperative Cardiac Arrest Patients

\begin{tabular}{|c|c|c|c|}
\hline Characteristic & Patients $(n=28)$ & Survival $(n=8)$ & $P$ value* \\
\hline \multicolumn{4}{|c|}{ Intubation before entering OR } \\
\hline Yes & 7 & $1(14.3)$ & 0.633 \\
\hline No & 21 & 7 (33.3) & \\
\hline \multicolumn{4}{|c|}{ Intubated state when leaving OR } \\
\hline Yes & 20 & $3(15)$ & $0.022^{\dagger}$ \\
\hline No & 8 & $5(62.5)$ & \\
\hline \multicolumn{4}{|l|}{ Arterial cannulation } \\
\hline Yes & 22 & $5(22.7)$ & 0.311 \\
\hline No & 6 & $3(50)$ & \\
\hline \multicolumn{4}{|l|}{ Central venous cannulation } \\
\hline Yes & 19 & $4(21.1)$ & 0.371 \\
\hline No & 9 & $4(44.4)$ & \\
\hline \multicolumn{4}{|c|}{ Intraoperative epinephrine usage } \\
\hline Yes & 11 & $2(18.2)$ & 0.419 \\
\hline No & 17 & $6(35.3)$ & \\
\hline \multicolumn{4}{|l|}{ Type of anesthesia } \\
\hline General anesthesia & 27 & $8(29.6)$ & 1.000 \\
\hline Spinal anesthesia & 1 & $0(0)$ & \\
\hline Other & 0 & $0(0)$ & \\
\hline
\end{tabular}

Values are presented as number (\%). OR: operating room. *Statistical analysis was conducted using Fisher's exact test. ${ }^{\dagger} \mathrm{P}$ value $<0.05$, statistically significant. 
The survival rate was significantly different by intubation state when leaving the OR $(\mathrm{P}=0.022)$.

Among five patients who received CPCR for less than 10 min, four patients achieved survival (80\%), whereas only four patients achieved survival among the 23 patients (17.4\%) who received CPCR for more than $10 \mathrm{~min}$ (Table 3). The most common event leading to perioperative cardiac arrest was hypovolemic shock (28.6\%, eight cases), followed by septic shock $(21.4 \%$, six cases), cardiogenic shock ( $17.9 \%$, five cases), and respiratory arrest ( $14.3 \%$, four cases). The rate of survival decreased in the order of cardiogenic shock $(80 \%$, four of five CPCR cases), respiratory arrest (75\%, three of four CPCR cases), septic shock (16.7\%, one of six CPCR cases) and hypovolemic shock ( $0 \%, 0$ of eight CPCR cases). When the surgical duration was short, the rate of survival tended to increase. There was, however, no significant difference between surgical duration and the survival rate $(\mathrm{P}=0.727)$. The caus- es of cardiac arrest were divided into anesthesia-related (3/3 cases, survival/CPCR cases), surgery-related ( $1 / 4$ cases), patient-related ( $4 / 20$ cases), and others ( $0 / 1$ case). The survival rate was significantly different by the duration of CPCR $(\mathrm{P}=$ $0.015)$, the event leading to cardiac arrest $(P=0.001)$, and the cause of cardiac arrest $(\mathrm{P}=0.036)$.

Among three anesthesia-related CPCR cases, two cases were caused by respiratory arrest occurring after the intravenous administration of pethidine, and one case was caused by stress-induced cardiomyopathy (SCMP) after the induction of general anesthesia. All perioperative CPCR and anesthesia-related CPCR cases are summarized in Tables 4 and 5, respectively.

The CPCR cases were divided into groups based on the age of 65, and the related factors were analyzed (Table 6). The older aged group showed higher survival rates than the other patients (35.7\% vs. $21.4 \%$ respectively). The older

Table 3. Characteristics of CPCR and Surgery in CPCR Cases

\begin{tabular}{|c|c|c|c|}
\hline Characteristic & Patients $(n=28)$ & Survival $(n=8)$ & P value* \\
\hline \multicolumn{4}{|l|}{ Time of cardiac arrest } \\
\hline Working hours & 12 & $3(25)$ & 1.000 \\
\hline Non-working hours & 16 & $5(31.3)$ & \\
\hline \multicolumn{4}{|l|}{ Intraoperative CPCR } \\
\hline Yes & 9 & $1(11.1)$ & 0.214 \\
\hline No & 19 & $7(36.8)$ & \\
\hline \multicolumn{4}{|l|}{ Duration of CPCR (min) } \\
\hline$\leq 10$ & 5 & $4(80)$ & $0.015^{\dagger}$ \\
\hline$>10$ & 23 & $4(17.4)$ & \\
\hline \multicolumn{4}{|l|}{ Event leading to cardiac arrest } \\
\hline Hypovolemic shock & 8 & $0(0)$ & $0.001^{\dagger}$ \\
\hline Septic shock & 6 & $1(16.7)$ & \\
\hline Cardiogenic shock & 5 & $4(80)$ & \\
\hline Respiratory arrest & 4 & $3(75)$ & \\
\hline Other & 5 & $0(0)$ & \\
\hline \multicolumn{4}{|l|}{ Department of surgery } \\
\hline Thoracic surgery & 3 & $2(66.7)$ & 0.083 \\
\hline Otolaryngology & 1 & $1(100)$ & \\
\hline General surgery & 13 & $5(38.5)$ & \\
\hline Neurosurgery, obstetrics and gynecology, orthopedics, urology & 11 & $0(0)$ & \\
\hline \multicolumn{4}{|l|}{ Duration of surgery $(\mathrm{h})$} \\
\hline$<1.5$ & 4 & $2(50)$ & 0.727 \\
\hline $1.5-3$ & 11 & $3(27.3)$ & \\
\hline$>3$ & 13 & $3(23.1)$ & \\
\hline \multicolumn{4}{|l|}{ Cause of cardiac arrest } \\
\hline Anesthesia-related & 3 & $3(100)$ & $0.036^{\dagger}$ \\
\hline Surgery-related & 4 & $1(25)$ & \\
\hline Patient-related & 20 & $4(20)$ & \\
\hline Unknown & 1 & $0(0)$ & \\
\hline
\end{tabular}

Values are presented as number (\%). CPCR: cardiopulmonary cerebral resuscitation. * Statistical analysis was conducted using Fisher's exact test. ${ }^{\dagger} \mathrm{P}$ value $<0.05$, statistically significant. 
aged group had a lower proportion of trauma patients ( $14.3 \%$ vs. $42.9 \%$ ), emergent surgery ( $42.9 \%$ vs. $71.4 \%)$, intraoperative CPCR cases (21.4\% vs. $42.9 \%)$, and a higher proportion of shorter duration CPCR (28.6\% vs. $7.1 \%)$.

For comparison with previous studies conducted in
Seoul [2], we analyzed the characteristics of the surgical patients at the two hospitals and the results are shown in Table 7. A total of nine cases of intraoperative cardiac arrests occurred in our hospital, and one patient survived (the incidence and mortality were 1.56 and 1.39 per 10,000

Table 4. Characteristics of Perioperative Cardiac Arrest Patients

\begin{tabular}{|c|c|c|c|c|c|c|c|c|}
\hline No & Age (yr) & Sex & ASA PS & $\begin{array}{l}\text { Surgical } \\
\text { procedure }\end{array}$ & Surgery & Department & $\begin{array}{c}\text { Event leading to } \\
\text { arrest }\end{array}$ & Outcome \\
\hline 1 & 85 & $\mathrm{~F}$ & 3 & Emergency & Total colectomy & GS & Septic shock & Died \\
\hline 2 & 84 & $\mathrm{~F}$ & 2 & Elective & TKR Lt. & os & Unknown & Died \\
\hline 3 & 43 & $\mathrm{~F}$ & 3 & Emergency & Emergency $\mathrm{C} / \mathrm{S}$ & OBGY & Amniotic fluid embolism & Died \\
\hline 4 & 82 & M & 2 & Elective & AVR with CABG & TS & Rt. heart failure & Survival \\
\hline 5 & 61 & M & 1 & Elective & Lap-cholecystectomy & GS & DIC & Died \\
\hline 6 & 27 & M & 5 & Emergency & Explorative thoracotomy & TS & Hypovolemic shock & Died \\
\hline 7 & 11 & $\mathrm{~F}$ & 2 & Elective & T\&A, systrunk surgery & ENT & Respiratory arrest & Survival \\
\hline 8 & 69 & M & 2 & Elective & DP \& splenectomy & GS & Hypovolemic shock & Died \\
\hline 9 & 82 & $\mathrm{~F}$ & 3 & Elective & Cystectomy & URO & Hypovolemic shock & Died \\
\hline 10 & 70 & $\mathrm{~F}$ & 2 & Elective & Lap-cholecystectomy & GS & AMI & Survival \\
\hline 11 & 46 & M & 3 & Elective & $\mathrm{KT}$, recipient & GS & Respiratory arrest & Survival \\
\hline 12 & 66 & $\mathrm{~F}$ & 3 & Emergency & I\&D, thigh, Rt. & OS & Septic shock & Died \\
\hline 13 & 82 & M & 2 & Elective & DG & GS & SCMP & Survival \\
\hline 14 & 76 & $\mathrm{~F}$ & 2 & Elective & Reversal of Hartmann's operation & GS & Septic shock & Died \\
\hline 15 & 62 & $\mathrm{~F}$ & 4 & Emergency & Primary repair, stomach & GS & Septic shock & Died \\
\hline 16 & 69 & M & 3 & Emergency & Explorative laparotomy & GS & Septic shock & Survival \\
\hline 17 & 3 & M & 2 & Emergency & Coil embolization, Craniectomy & NS & Brain stem failure & Died \\
\hline 18 & 82 & M & 2 & Emergency & SB R\&A & GS & Respiratory arrest & Survival \\
\hline 19 & 2 & M & 4 & Emergency & Craniotomy & NS & Cardiogenic shock & Died \\
\hline 20 & 63 & $\mathrm{~F}$ & 3 & Emergency & Hartmann's operation & GS & Septic shock & Died \\
\hline 21 & 57 & M & 4 & Emergency & Craniotomy & NS & Hypovolemic shock & Died \\
\hline 22 & 33 & $\mathrm{~F}$ & 2 & Emergency & Emergency $\mathrm{C} / \mathrm{S}$ & OBGY & PTE & Died \\
\hline 23 & 33 & M & 3 & Emergency & Decompressive C/E & NS & Hypovolemic shock & Died \\
\hline 24 & 69 & M & 2 & Elective & PLF L1-5, PLIF L2-4 & OS & Respiratory arrest & Died \\
\hline 25 & 85 & M & 4 & Emergency & SB R\&A & GS & Hypovolemic shock & Died \\
\hline 26 & 48 & $\mathrm{~F}$ & 3 & Elective & MVR & TS & Cardiogenic shock & Survival \\
\hline 27 & 60 & M & 5 & Emergency & Splenectomy & GS & Hypovolemic shock & Died \\
\hline 28 & 67 & $\mathrm{~F}$ & 3 & Emergency & Emergency C/E & NS & Hypovolemic shock & Died \\
\hline
\end{tabular}

ASA PS: American Society of Anesthesiologists physical status, TKR: total knee replacement, C/S: cesarean section, AVR: aortic valve replacement, CABG: coronary artery bypass graft, Lap: laparoscopic, T\&A: tonsillectomy \& adenoidectomy, DP: distal pancreatectomy, KT: kidney transplantation, I\&D: incision \& drainage, DG: distal gastrectomy, SB R\&A: small bowel resection \& anastomosis, C/E: craniectomy, PLF: posterior lateral fusion, PLIF: posterior lumbar interbody fusion, MVR: mitral valve replacement, GS: general surgery, OS: orthopedics, OBGY: obstetrics and gynecology, TS: thoracic surgery, ENT: otolaryngology, URO: urology, DIC: disseminated intravascular coagulation, AMI: acute myocardial infarction, SCMP: stressinduced cardiomyopathy, PTE: pulmonary thromboembolism.

Table 5. Adverse Events in Anesthesia-Related Cardiac Arrest

\begin{tabular}{|c|c|c|c|c|c|c|c|c|c|}
\hline No & Age (yr) & Sex & ASA PS & Emergency & Diagnosis & Surgery & Cause & Comorbidity & Outcome \\
\hline 1 & 82 & $M$ & 2 & Yes & $\begin{array}{l}\text { Impending stran } \\
\text { gulation }\end{array}$ & SB R\&A & $\begin{array}{l}\text { Before CPCR, IV pethidine } 25 \mathrm{mg} \text { was in- } \\
\text { jected postoperatively at ICU }\end{array}$ & COPD & Survival \\
\hline 2 & 46 & $M$ & 3 & No & ESRD & $\mathrm{KT}$, recipient & $\begin{array}{l}\text { Before CPCR, IV pethidine } 25 \mathrm{mg} \text { was in- } \\
\text { jected postoperatively at ICU }\end{array}$ & HTN & Survival \\
\hline 3 & 82 & $M$ & 2 & No & AGC & DG & $\begin{array}{l}\text { After an induction and intubation, a total } \\
\text { of } 500 \mu \mathrm{g} \text { of phenylephrine was admin- } \\
\text { istered for } 10 \text { min due to low blood } \\
\text { pressure. Sudden cardiac arrest oc- } \\
\text { curred afterward. }\end{array}$ & A-fib & Survival \\
\hline
\end{tabular}

ASA PS: American Society of Anesthesiologists physical status, ESRD: end-stage renal disease, AGC: advanced gastric cancer, SB R\&A: small bowel resection \& anastomosis, KT: kidney transplantation, DG: distal gastrectomy, CPCR: cardiopulmonary cerebral resuscitation, IV: intravenous, ICU: intensive care unit, COPD: chronic obstructive pulmonary disease, HTN: hypertension, A-fib: atrial fibrillation. 
Table 6. Analysis of CPCR Cases Subgrouped by Age 65

\begin{tabular}{cccccc}
\hline Age $(\mathrm{yr})$ & Survival $(\mathrm{n}=8)$ & Trauma & Emergency surgery & Intraoperative CPCR & CPCR duration, $\leq 10$ min \\
\hline$<65(\mathrm{n}=14)$ & $3(21.4)$ & $6(42.9)$ & $10(71.4)$ & $6(42.9)$ & $1(7.1)$ \\
$\geq 65(\mathrm{n}=14)$ & $5(35.7)$ & $2(14.3)$ & $6(42.9)$ & $3(21.4)$ & $4(28.6)$ \\
\hline
\end{tabular}

Values are presented as number (\%). CPCR: cardiopulmonary cerebral resuscitation.

Table 7. Comparison of Surgical Patient Characteristics between Hospital in Youngdong Province and Seoul

\begin{tabular}{|c|c|c|c|}
\hline Characteristics & Hospital in Youngdong $(n=57,746)$ & Hospital in Seoul* $(n=457,529)$ & $\mathrm{P}$ value $^{\dagger}$ \\
\hline Incidence of CPCR (per 10,000 anesthesia) & $1.56^{\ddagger}$ & 0.66 & - \\
\hline Mortality (per 10,000 anesthesia) & $1.39^{\ddagger}$ & 0.21 & - \\
\hline \multicolumn{4}{|l|}{ Age $(y r)$} \\
\hline$<65$ & $40,852(70.7)$ & $365,236(79.8)$ & $<0.001^{\|}$ \\
\hline$\geq 65$ & $16,894(29.3)$ & $92,293(20.2)$ & \\
\hline \multicolumn{4}{|l|}{ Sex } \\
\hline Male & $28,979(50.2)$ & $213,372(47)$ & $<0.001^{\|}$ \\
\hline Female & $28,767(49.8)$ & $244,157(53)$ & \\
\hline \multicolumn{4}{|l|}{ ASA PS class ${ }^{\S}$} \\
\hline Low (I-II) & $50,222(90.8)$ & $424,378(92.8)$ & $<0.001^{\|}$ \\
\hline High (III-V) & $5,084(9.2)$ & $32,809(7.2)$ & \\
\hline \multicolumn{4}{|l|}{ Elective surgery } \\
\hline Yes & $51,158(88.6)$ & $439,383(96)$ & $<0.001^{\|}$ \\
\hline No & 6,588 (11.4) & $18,146(4)$ & \\
\hline
\end{tabular}

Values are presented as number (\%). CPCR: cardiopulmonary cerebral resuscitation, ASA PS: American Society of Anesthesiologists physical status. *Collated data derived from a previous study [2]. 'Statistical analysis was conducted using $\chi^{2}$ test. ${ }^{\ddagger}$ Values are presented when the analysis was limited to patients with intraoperative cardiac arrest. ${ }^{\S}$ Values are presented when the analysis was limited to patients with ASA PS classification I-V.

" $P$ value $<0.05$, statistically significant.

anesthesia cases, respectively). There were significant differences between the two hospitals in the factors of age, sex, ASA PS classification, and the proportion of elective surgery $(\mathrm{P}<0.001)$.

\section{DISCUSSION}

For the past fifty years, the incidence and mortality of perioperative cardiac arrest have decreased worldwide, although the average ASA PS classification has increased [1]. Improvements in patient safety, advancements in patient care, surgical techniques, anesthetic methods, multiple guidelines and healthcare team training have all contributed to the decrease in incidence and mortality $[1,2]$. But there are only a few studies on this topic in Korea.

According to the study in Seoul [2], the reported incidence and mortality rate of perioperative cardiac arrest were low, at 0.66 and 0.21 per 10,000 anesthesia cases, respectively. The study was the largest retrospective study on this subject in Korea, but it was limited to subjects with intraoperative cardiac arrests during non-cardiac surgeries. Therefore, the study had a risk of underestimating the perioperative incidence and mortality rate in Korea.
The incidence of perioperative cardiac arrest is affected by the proportion of elderly patients, sex, the ASA PS classification, comorbidities (sepsis, trauma, multi-organ failure, etc.), emergency surgery, surgical technique, the length of surgery, and the anesthesia method $[2,4,5,10]$. It is known that an elderly age increases the risk of perioperative cardiac arrest $[5,11]$ and decreases the survival rate [12]. In the present study, age divided below or above 65 years, was significantly related to the incidence of cardiac arrest, but not related to the survival rate. The survival rate of the elderly group was higher than that of the other group, which might have been due to the lower number of patients with trauma, emergency, and short duration of CPCR (Table 6).

Male sex is regarded to increase the incidence of perioperative cardiac arrest $[5,10]$. Our study showed a higher incidence of cardiac arrest in the male group, but the difference was not significant. A high ASA PS classification and emergency surgery have been reported as risk factors for perioperative cardiac arrest, and are the predictive factors for mortality after cardiac arrest $[5,13]$. In the present study, perioperative cardiac arrest occurred more in patients with higher ASA PS classifications and in the emergency surgery group. 
Table 2 shows that the postoperative maintenance of the ETT was significantly associated with low survival rates (P $=0.022$ ). This is because the ETT would be maintained in patients with poor test values, such as arterial blood gas analysis during surgery, and ETT maintenance itself might adversely affect to vital organs like lungs.

When comparing the groups divided by a CPCR period of $10 \mathrm{~min}$, the survival rate was four times higher in the short CPCR time group than in the other group (80\% vs. $17.4 \%, \mathrm{P}$ $=0.015)$. A systemic review of seven CPCR studies [14] reported that neurologic outcomes might be more favorable when the CPCR duration is shorter. Our result is consistent with a previous study that reported that the CPCR method currently in use was the most effective in the first 10 to 15 min and after $15 \mathrm{~min}$, the possibility of achieving the resuscitation of spontaneous circulation (ROSC) with a good functional recovery declined to less than $2 \%$ [9].

Hypovolemic shock was the most common event leading to cardiac arrest and showed the lowest survival rate. It is known as a major factor for cardiac arrest and occurs frequently in traumatic patients [15]. In the present study, emergency surgery was performed because of trauma in six out of eight patients with hypovolemic shock (75\%). In the patients who received traumatic emergency surgery of the abdomen, brain, heart, or musculoskeletal system, blood loss caused changes in the ASA PS classification. Because blood loss is usually associated with high morbidity in trauma patients, excessive intraoperative bleeding may increase the incidence of cardiac arrest. Also, if shock occurred prior to surgery due to excessive bleeding, the relative risk of cardiac arrest rose to 2.62 [4].

According to previous studies, the incidence of anesthesia-related cardiac arrest is 0.5 to 3.35 per 10,000 anesthesia cases $[5,10,16]$. In this study, the incidence of anesthesia-related cardiac arrest was $10.7 \%$ (three of 28 CPCR cases) and 0.52 per 10,000 anesthesia cases. An et al. [17] reported a $4.3 \%$ rate of anesthesia-related cardiac arrests in patients with non-cardiac surgery, whereas Newland et al. [13] and Sprung et al. [18] reported similar incidences ( $10.4 \%$ and $10.8 \%$, respectively), consistent with the present study. The study conducted in Seoul [2] also showed a similar incidence of anesthesia-related cardiac arrest (13.3\%). Mortality in anesthesia-related cardiac arrest has decreased over time [1]. The present study showed a low mortality rate in anesthesia-related cardiac arrest (0\%). Ellis et al. [10] suggested that anesthesia-related cardiac arrest had lower mortality than other factor-related arrests
(29\% vs. $70 \%$, respectively).

There were three anesthesia-related cardiac arrests in this study (Table 5). Two cases were caused by respiratory depression after postoperative pethidine administration in the intensive care unit. In a comparative study with tramadol [19], pethidine showed a significant suppression on the respiratory rate and reductions in the 1-min ventilation volume. Respiratory suppression usually occurs within 24 $\mathrm{h}$ of surgery and even though it is usually preventable, $77 \%$ of patients who experience it suffer fatal complications, such as death or serious brain damage [20]. Even though respiratory suppression by opioids is rare in patients with ASA PS classifications from 1 to 3 , attention should be paid to patients who are very young, obese, have sleep apnea, or have ASA PS classifications of 4 or 5 [21].

The other case was caused by SCMP. In that case, the preoperative echocardiogram performed two days before the surgery revealed non-valvular atrial fibrillation with a normal left ventricular ejection fraction (LVEF) of $68 \%$. After induction and intubation, a total of $500 \mu \mathrm{g}$ of phenylephrine was administered for $10 \mathrm{~min}$. Then, sudden cardiac arrest occurred. SCMP was clinically suspected according to the intraoperative echocardiogram that showed a decreased LVEF (50\%) and apical akinesia. Coronary angiogram performed after the ROSC showed normal coronary arteries. SCMP may occur due to physical stress, emotional stress, catecholamine excess, and other critical conditions [22]. It is difficult to determine the exact cause, but in this patient, the administration of phenylephrine could have triggered the SCMP.

Three to $23 \%$ of SCMP is reportedly caused by surgery, and approximately $17 \%$ of the SCMP patients in hospitals had general anesthesia within the past week [23]. The incidence of SCMP in the hospital has been underestimated. However, SCMP can occur after any kind of surgery. Given this, anesthesiologists should become more familiar with the symptoms, diagnosis, and treatment of SCMP. In the event of an unexpected cardiovascular collapse, not only acute coronary syndrome but also SCMP should be suspected.

When limiting the analysis in this study to intraoperative CPCR cases only, the incidence and mortality were 1.56 and 1.39 per 10,000 anesthesia cases, respectively (one survival case of nine intraoperative CPCR). The rates were still higher than those of the Seoul study [2] (0.66 vs. 1.56, 0.21 vs. 1.39 per 10,000 anesthesia cases, respectively). The authors inferred that the difference was attributable to the demographic characteristics of the cities where the hospi- 
tals are located. Despite the worldwide improvement in perioperative mortality over time, the degree of improvement shows regional differences correlated with the country's Human Development Index. This may be due to the fact that developed countries have been investing in medical care systems, and/or developing countries have higher rates of trauma/emergency surgery and advanced disease [6]. If inter-regional differences exist in one country, regional gaps in perioperative cardiac arrest rates may occur.

The proportion of elderly patients aged 65 or more who underwent surgery in our hospital was significantly higher than that of the hospital in Seoul $(29.3 \%$ vs. $20.2 \%, \mathrm{P}<$ 0.001 ) (Table 7). As of 2017, the proportion of the elderly population aged 65 or more in Gangwon-do was $17.5 \%$, which is the fourth-highest by city and district units in Korea [24]. However, the ratios in Seoul and Gyeonggi-do are lower than the national average of $13.7 \%$, which account for $13.3 \%$ and $11.1 \%$, respectively. These demographic characteristics have led to differences in the groups of patients visiting each hospital.

Considering that the incidence of perioperative cardiac arrest is affected by the proportion of the elderly population $[2,5]$ and the prevalence of chronic disease tends to increase with higher age, the variation in patient age at the two hospitals is expected to affect the incidence of perioperative cardiac arrest. Also, the ratio of emergency surgery was significantly higher in our hospital than in the study in Seoul (11.4\% vs. $4 \%, \mathrm{P}<0.001$ ) (Table 7 ). Given that emergency and traumatic surgery led to a higher incidence of and mortality from perioperative cardiac arrest than scheduled surgeries and non-traumatic surgery [5], this difference could have a significant effect on the incidence and mortality of perioperative cardiac arrest in our hospital.

When the surgical patients of the hospitals were divided into two groups according to ASA PS classifications (Low: III, High: III-V), the proportion of the higher ASA PS group in our hospital was significantly higher than in the hospital in Seoul $(9.2 \%$ vs. $7.2 \%, \mathrm{P}<0.001)$. This result is presumed to be due to the higher average age and the higher rate of emergency surgery of our surgical patients. As mentioned above, high ASA PS classification increases the incidence of cardiac arrest, and it may be the cause of the difference in perioperative cardiac arrest rates between the two hospitals.

In conclusion, the incidence and mortality rate of perioperative cardiac arrest were 4.85 and 3.46 per 10,000 anesthesia cases, respectively, and the results showed a regional gap in perioperative cardiac arrest rates in Korea. The re- sults could be attributed to the differences in the patients who underwent anesthesia and surgery, whose composition differed from that of the urban population. Further research should be conducted on the regional inequality of perioperative cardiac arrest rates from various regions. Also, policies and public resource allocation to reduce the regional gap in perioperative cardiac arrest rates should be implemented.

\section{CONFLICTS OF INTEREST}

No potential conflict of interest relevant to this article was reported.

\section{AUTHOR CONTRIBUTIONS}

Conceptualization: Hong-Seuk Yang. Data acquisition: Hyun-Soo Kim. Formal analysis: Young-Mu Kim, Jae-Ho Lee. Supervision: Jin Sun Kim. Original draft: Young-Mu Kim. Review \& editing: Hong-Seuk Yang, Jin Sun Kim, Young-Mu Kim.

\section{ORCID}

Young-Mu Kim, https://orcid.org/0000-0002-0286-1010

Jae-Ho Lee, https://orcid.org/0000-0002-2965-5794

Hyun-Soo Kim, https://orcid.org/0000-0001-6817-7214

Jin Sun Kim, https://orcid.org/0000-0002-3753-2997

Hong-Seuk Yang, https://orcid.org/0000-0003-2023-8705

\section{REFERENCES}

1. Bainbridge D, Martin J, Arango M, Cheng D; Evidence-based Peri-operative Clinical Outcomes Research (EPiCOR) Group. Perioperative and anaesthetic-related mortality in developed and developing countries: a systematic review and meta-analysis. Lancet 2012; 380: 1075-81.

2. Choi YJ, Han SU, Woo S, Ro YJ, Yang HS. Perioperative cardiac arrest in 457,529 anesthetized patients at a single teaching hospital in Korea: a retrospective study. Anesth Pain Med 2014; 9: $144-51$

3. Vane MF, do Prado Nuzzi RX, Aranha GF, da Luz VF, Malbouisson LMS, Gonzalez MMC, et al. Perioperative cardiac arrest: an evolutionary analysis of the intra-operative cardiac arrest incidence in tertiary centers in Brazil. Braz J Anesthesiol 2016; 66: $176-82$

4. Siriphuwanun V, Punjasawadwong Y, Lapisatepun W, Charu- 
luxananan S, Uerpairojkit K. Incidence of and factors associated with perioperative cardiac arrest within 24 hours of anesthesia for emergency surgery. Risk Manag Healthc Policy 2014; 7: 155-62.

5. Braz LG, Módolo NS, do Nascimento P Jr, Bruschi BAM, Castiglia YMM, Ganem EM, et al. Perioperative cardiac arrest: a study of 53,718 anaesthetics over 9 yr from a Brazilian teaching hospital. Br J Anaesth 2006; 96: 569-75.

6. Braghiroli KS, Braz JRC, Rocha B, El Dib R, Corrente JE, Braz MG, et al. Perioperative and anesthesia-related cardiac arrests in geriatric patients: a systematic review using meta-regression analysis. Sci Rep 2017; 7: 2622.

7. Chang SC, Chung KS, Lee SH. Statistical analysis of the postoperative mortality. Korean J Anesthesiol 1976; 9: 107-11.

8. Lee JH, Kim EK, Song IK, Kim EH, Kim HS, Kim CS, et al. Critical incidents, including cardiac arrest, associated with pediatric anesthesia at a tertiary teaching children's hospital. Paediatr Anaesth 2016; 26: 409-17.

9. Reynolds JC, Frisch A, Rittenberger JC, Callaway CW. Duration of resuscitation efforts and functional outcome after out-of-hospital cardiac arrest: when should we change to novel therapies? Circulation 2013; 128: 2488-94.

10. Ellis SJ, Newland MC, Simonson JA, Peters KR, Romberger DJ, Mercer DW, et al. Anesthesia-related cardiac arrest. Anesthesiology 2014; 120: 829-38.

11. Nunnally ME, O'Connor MF, Kordylewski H, Westlake B, Dutton RP. The incidence and risk factors for perioperative cardiac arrest observed in the national anesthesia clinical outcomes registry. Anesth Analg 2015; 120: 364-70.

12. Ramachandran SK, Mhyre J, Kheterpal S, Christensen RE, Tallman K, Morris M, et al. Predictors of survival from perioperative cardiopulmonary arrests: a retrospective analysis of 2,524 events from the Get With The Guidelines-Resuscitation registry. Anesthesiology 2013; 119: 1322-39.

13. Newland MC, Ellis SJ, Lydiatt CA, Peters KR, Tinker JH, Romberger DJ, et al. Anesthetic-related cardiac arrest and its mortality: a report covering 72,959 anesthetics over 10 years from a US teaching hospital. Anesthesiology 2002; 97: 108-15.
14. Welbourn C, Efstathiou N. How does the length of cardiopulmonary resuscitation affect brain damage in patients surviving cardiac arrest? A systematic review. Scand J Trauma Resusc Emerg Med 2018; 26: 77.

15. Toledo FO, Gonzalez MM, Sebbag I, Lelis RG, Aranha GF, Timerman S, et al. Outcomes of patients with trauma and intraoperative cardiac arrest. Resuscitation 2013; 84: 635-8.

16. Zuercher M, Ummenhofer W. Cardiac arrest during anesthesia. Curr Opin Crit Care 2008; 14: 269-74.

17. An JX, Zhang LM, Sullivan EA, Guo Q1, Williams JP. Intraoperative cardiac arrest during anesthesia: a retrospective study of 218,274 anesthetics undergoing non-cardiac surgery. Chin Med J 2011; 124: 227-32.

18. Sprung J, Warner ME, Contreras MG, Schroeder DR, Beighley CM, Wilson GA, et al. Predictors of survival following cardiac arrest in patients undergoing noncardiac surgery: a study of 518,294 patients at a tertiary referral center. Anesthesiology 2003; 99: 259-69.

19. Tarkkila P, Tuominen M, Lindgren L. Comparison of respiratory effects of tramadol and pethidine. Eur J Anaesthesiol 1998; 15: 64-8.

20. Lee LA, Caplan RA, Stephens LS, Posner KL, Terman GW, Voepel-Lewis T, et al. Postoperative opioid-induced respiratory depression: a closed claims analysis. Anesthesiology 2015; 122: 659-65.

21. Dahan A, Aarts L, Smith TW. Incidence, reversal, and prevention of opioid-induced respiratory depression. Anesthesiology 2010; 112: 226-38.

22. Littlejohn FC, Syed O, Ornstein E, Connolly ES, Heyer EJ. Takotsubo cardiomyopathy associated with anesthesia: three case reports. Cases J 2008; 1: 227.

23. Hessel EA. Takotsubo cardiomyopathy and its relevance to anesthesiology: a narrative review. Can J Anaesth 2016; 63: 105974.

24. Korean Statistical Information Service. Population census. Statistics Korea [serial on the Internet]. 2017 [cited 2019 Aug 13]. Available from http://kosis.kr/statHtml/statHtml.do?orgId $=101 \&$ tblId =DT_1IN1503\&conn_path=I2. 